\title{
The secreted glycoprotein lubricin protects cartilage surfaces and inhibits synovial cell overgrowth
}

\author{
David K. Rhee,,1,2 Jose Marcelino,,1,2 MacArthur Baker, ${ }^{3}$ Yaoqin Gong, ${ }^{1,2}$ Patrick Smits, ${ }^{4}$ \\ Véronique Lefebvre, ${ }^{4}$ Gregory D. Jay, ${ }^{5,6}$ Matthew Stewart, ${ }^{7}$ Hongwei Wang, ${ }^{1}$ \\ Matthew L. Warman, ${ }^{1,2}$ and John D. Carpten ${ }^{3}$
}

\begin{abstract}
1Department of Genetics and ${ }^{2}$ Center for Human Genetics, Case Western Reserve University School of Medicine and University Hospitals of Cleveland, Cleveland, Ohio, USA. ${ }^{3}$ Cancer Genetics Branch, National Human Genome Research Institute, Bethesda, Maryland, USA.

${ }^{4}$ Department of Biomedical Engineering and Orthopaedic Research Center, Lerner Research Institute, Cleveland Clinic Foundation, Cleveland, Ohio, USA. ${ }^{5}$ Department of Medicine and ${ }^{6}$ Division of Engineering, Rhode Island Hospital and Brown University, Providence, Rhode Island, USA. ${ }^{7}$ Department of Orthopaedics, Case Western Reserve University School of Medicine and University Hospitals of Cleveland, Cleveland, Ohio, USA.
\end{abstract}

\begin{abstract}
The long-term integrity of an articulating joint is dependent upon the nourishment of its cartilage component and the protection of the cartilage surface from friction-induced wear. Loss-of-function mutations in lubricin (a secreted glycoprotein encoded by the gene PRG4) cause the human autosomal recessive disorder camptodactyly-arthropathy-coxa vara-pericarditis syndrome (CACP). A major feature of CACP is precocious joint failure. In order to delineate the mechanism by which lubricin protects joints, we studied the expression of Prg4 mRNA during mouse joint development, and we created lubricin-mutant mice. Prg4 began to be expressed in surface chondrocytes and synoviocytes after joint cavitation had occurred and remained strongly expressed by these cells postnatally. Mice lacking lubricin were viable and fertile. In the newborn period, their joints appeared normal. As the mice aged, we observed abnormal protein deposits on the cartilage surface and disappearance of underlying superficial zone chondrocytes. In addition to cartilage surface changes and subsequent cartilage deterioration, intimal cells in the synovium surrounding the joint space became hyperplastic, which further contributed to joint failure. Purified or recombinant lubricin inhibited the growth of these synoviocytes in vitro. Tendon and tendon sheath involvement was present in the ankle joints, where morphologic changes and abnormal calcification of these structures were observed. We conclude that lubricin has multiple functions in articulating joints and tendons that include the protection of surfaces and the control of synovial cell growth.
\end{abstract}

\section{Introduction}

In an articulating joint, such as the human knee, cartilage can be subjected to compressive and frictional forces several million times annually (1). Adult chondrocytes do not normally divide in vivo (2), and defects in cartilage surfaces are not self-repairing (3). Therefore, for a joint to maintain its function throughout a lifetime of use, there must be biologic mechanisms that help minimize damage resulting from activities of daily living. That the protection of the cartilage surface is imperfect is amply demonstrated by the prevalence of osteoarthritis in human populations (4). In addition to being subjected to extreme force, cartilage is avascular, deriving its nourishment from synovial fluid, a filtrate of blood that has components added and removed by the joint capsule's intimal lining cells, the synoviocytes (5).

Lubricin, a product of the gene proteoglycan 4 (PRG4) (Figure $1 \mathrm{~A})$, is a major component of synovial fluid and participates in the boundary lubrication of synovial joints (6-9). Purified initially from bovine joint fluid, where its concentration is estimated to be greater

Nonstandard abbreviations used: CACP, camptodactyly-arthropathy-coxa varapericarditis syndrome; HAPO, hemangiopoietin; MSF, megakaryocyte stimulating factor; PCNA, proliferating cell nuclear antigen; PRG4, proteoglycan 4; SZP, superficial zone protein.

Conflict of interest: The authors have declared that no conflict of interest exists.

Citation for this article: J. Clin. Invest. 115:622-631 (2005)

doi:10.1172/JCI200522263. than $30 \mu \mathrm{g} / \mathrm{ml}$, lubricin is an O-linked glycosylated protein (10) that is highly expressed by synoviocytes (11). PRG4 also encodes the related gene products superficial zone protein (SZP), megakaryocyte-stimulating factor (MSF), and hemangiopoietin (HAPO). SZP is expressed by superficial zone chondrocytes at the cartilage surface but not by intermediate or deep zone chondrocytes $(12,13)$. MSF was purified from human urine and found to stimulate growth of platelet-forming cells in vitro (14). HAPO was identified as a factor capable on inducing growth of hematopoietic and endothelial stem/ progenitor cells (15). Since patients with camptodactyly-arthropathy-coxa vara-pericarditis syndrome (CACP) have loss-of-function mutations in PRG4 but have no hematologic abnormalities, the in vivo functions of MSF and HAPO remain undetermined. Herein, we use "lubricin" when referring to the protein products expressed by cells within articulating joints, recognizing that alternative splice forms and post-translationally modified versions of the protein with additional biologic properties may exist. The essential role for lubricin in maintaining joint integrity was demonstrated by the identification of disease-causing mutations in patients with the autosomal recessive disorder CACP (11). Individuals with CACP have normalappearing joints at birth but with advancing age develop joint failure associated with noninflammatory synoviocyte hyperplasia and subintimal fibrosis of the synovial capsule (16).

Lubricin contains multiple protein domains that likely contribute to its diverse biologic properties (Figure 1A). Analysis of 

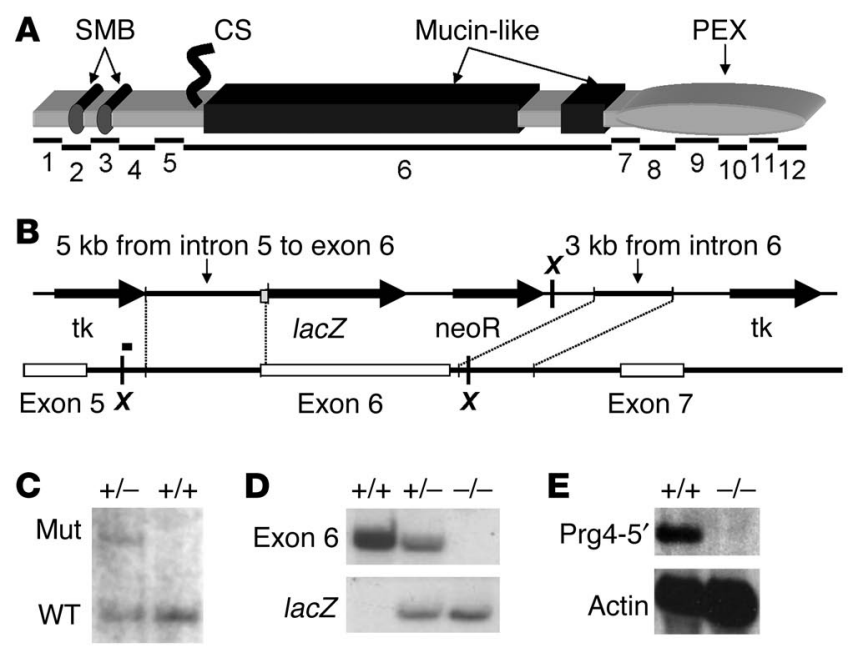

Figure 1

Lubricin structure and Prg4 gene targeting in mice. (A) Schematic depicting the domain structure of lubricin and the portions encoded by each of the Prg 4 gene's 12 coding exons. The amino-terminus is at the left and the carboxyl-terminus at the right. The amino-terminal portion contains 2 domains of $60 \%$ similarity to the somatomedin B (SMB) domains of vitronectin. Exons 2, 4, and 5 are subject to alternative splicing. The mucin-like domain, encoded by exon 6 , comprises 25 and 6 repeats of the sequences KEPAPTTT/P and XXTTTX, respectively. Carboxyl-terminal to the mucin-like domains is a hemopexin (PEX) domain, whose similarity with vitronectin is $50 \%$ and with several members of the matrix metalloproteinase family is $40 \%$. CS, covalently linked chondroitin sulfate side chain. (B) The targeting construct was intended to create a lubricin-E. coli $\beta$-gal fusion protein by substituting an in-frame lac $Z$ coding sequence for exon 6 . Xba I sites $(X)$ are marked. The site of the probe used to detect correct $5^{\prime}$ targeting is shown as a bar above the $5^{\prime} \mathrm{Xba} / \mathrm{site}$. tk, thymidine kinase. (C) Southern blot demonstrating correct $5^{\prime}$ targeting in an ES cell clone $(+/-)$ in contrast to a nontargeted clone $(+/+)$ using a probe that was $5^{\prime}$ of the targeting arm that recognizes the wild-type allele as an 8-kb $X$ ba I fragment and the targeted mutant allele (Mut) as a 10.3-kb Xba I fragment. (D) Probes derived from exon 6 and from lacZ, respectively confirming targeting by Southern blot in wild-type $(+/+)$, heterozygous $(+/-)$, and homozygous mutant $(-/-)$ mice. (E) No Prg 4 transcript is detected in the mice that are homozygous for the targeted allele using a cDNA probe representing exons 1-3 ( $\left.\mathrm{Prg} 4-5^{\prime}\right)$, which is upstream of the targeted exon.

lubricin's amino acid sequence has revealed it to be related to vitronectin (14). Both proteins contain somatomedin B (SMB) and hemopexin-like (PEX) domains, which have approximately $60 \%$ sequence similarity in these regions. In the case of vitronectin, SMB and PEX domains have been suggested to regulate the complement and coagulation systems, mediate extracellular matrix attachment, and promote cell attachment and proliferation (17-19). Despite this multitude of biologic activities, vitronectin-knockout mice have no obvious clinical phenotype (20). Unlike vitronectin, lubricin contains a large, central, mucin-like domain, characterized by the repeat motif KEPAPTTT/P, which is subject to extensive O-linked glycosylation $(10,21)$. The abundance of negatively charged sugars in this domain contributes to the protein's boundary lubrication of the cartilage surface due to strong repulsive hydration forces (8). Diverse biologic roles have been attributed to other mucin domain-containing proteins, including the protection of epithelial surfaces (22), the regulation of cell differentiation
(23), and the control of cell growth (24). Although domain similarities with other proteins may suggest biologic roles for lubricin, these predictions require experimental confirmation. Toward this goal, we have created lubricin-mutant $\left(\operatorname{Prg}^{-/-}\right)$mice and have studied these mice to explore specific functions of lubricin at the cartilage surface and in the control of synoviocyte growth.

\section{Results}

Lubricin $m R N A$ is expressed by superficial chondrocytes and synoviocytes. Prg4 is expressed after developing joints have begun to cavitate (Figure 2A). At the early stages of this process, low levels of Prg4 expression are detected in cells near the newly formed joint surface. At later stages of morphogenesis, strong Prg4 expression is observed in cartilage surface cells (superficial zone chondrocytes) and in the newly forming synovium. Postnatally, strong expression of $\operatorname{Prg} 4$ persists in the surface chondrocytes and in synovial intimal cells (Figure 2B).

Prg4 ${ }^{-/-}$mice are viable and fertile. The Prg4 locus was targeted by homologous recombination in ES cells. Correct targeting was confirmed by Southern blotting using flanking $5^{\prime}$ (Figure 1C) and 3' (data not shown) probes. The ES cells were used to produce mice homozygous and heterozygous for the Prg 4 targeted allele. The targeted allele was intended to create a Prg4-lacZ fusion transcript; however, no mutant RNA species was detected in Northern blots containing liver RNA from $\mathrm{Prg}^{4^{-/}}$mice using a probe that represents exons $1-3$ of the cDNA (Figure 1E), which is upstream of the targeted exon, or a probe that represents exons 7-12 (data not shown), which is downstream of the targeted exon. RT-PCR studies of synovial and liver mRNA demonstrated aberrant mRNA splicing from the targeted Prg4 allele (data not shown), which we suspect led to nonsense mediated mRNA decay. Prg 4 mRNA was also undetectable by in situ hybridization in $\operatorname{Prg}^{-{ }^{--}}$cartilage (data not shown). At weaning, the number of $\mathrm{Prg}^{-/-}$mice was not statistically significantly different from the expected Mendelian frequencies (of the first 61 weaned mice from heterozygous matings, 16 were wild type, 13 were mutant, and 32 were heterozygous; $P=0.8$ by $\chi^{2}$ analysis with 2 degrees of freedom), which indicated that there was no strong selection against the genotype in utero or in the perinatal period. $\mathrm{Prg}^{-/-}$ mice did not have noticeably reduced fertility or life expectancy.

Prg4 $4^{-1-}$ mice develop clinical and radiologic signs of joint disease with increasing age. During the first few months of life, there were no gross phenotypic changes in the mutant mice. By 4 months of age, the mice began to exhibit swelling of the tarsal (ankle) joints and flexion deformity of the hind paws (Figure 3, A and B). They also developed an abnormal hopping gait. No differences in joint shape or structure were observed between $\operatorname{Prg}^{-/-}$and wild-type mice in the newborn period. Radiology studies revealed joint involvement at 4 months of age (Figure 3, E-H). Although it was not possible to directly assess symptoms of joint pain in mice, we did not observe signs of distress in the mutant mice, such as decreased levels of activity or grooming, which led us to infer that they did not experience significant joint pain. Joint pain is also not a common symptom in younger patients with CACP (authors' unpublished observations).

Prg4 $4^{-1}$ mice develop histologic abnormalities in their articulating joints. Newborn $\mathrm{Prg}^{-/-}$mice had normal-appearing cartilage histology. At 2 months of age, their joints were significantly different from wild-type and heterozygous $\left(\operatorname{Prg}^{+/-}\right)$mice (Figure 4, A and B). $\mathrm{Prg}^{-/-}$mice had synovial hyperplasia and subintimal fibrosis, proteinaceous deposits on the cartilage surface, and irregular cartilage 

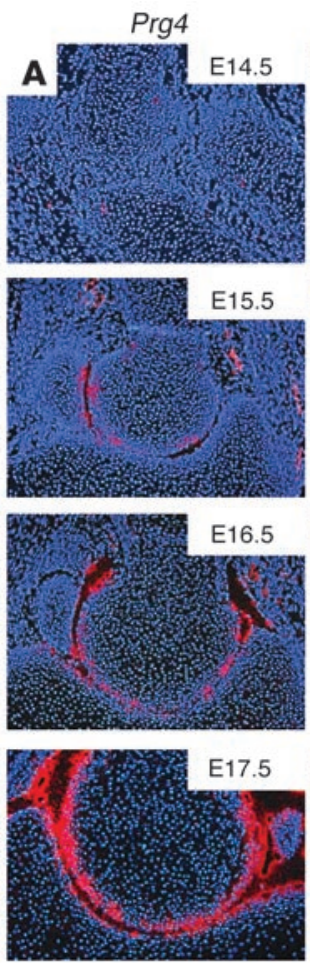

Gdf5
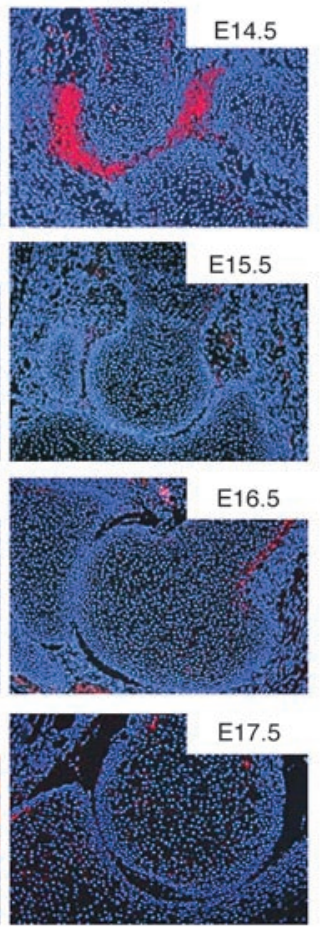
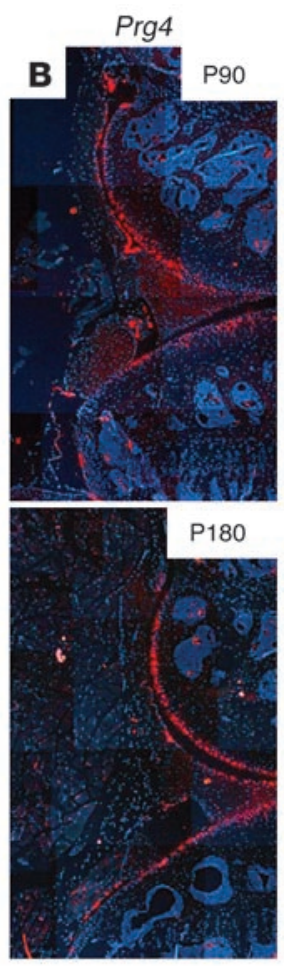
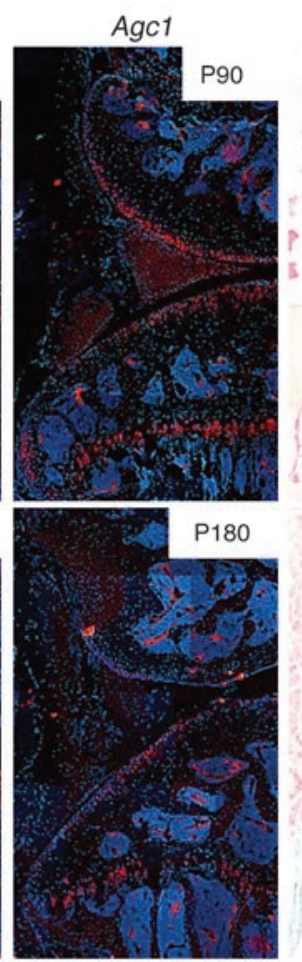

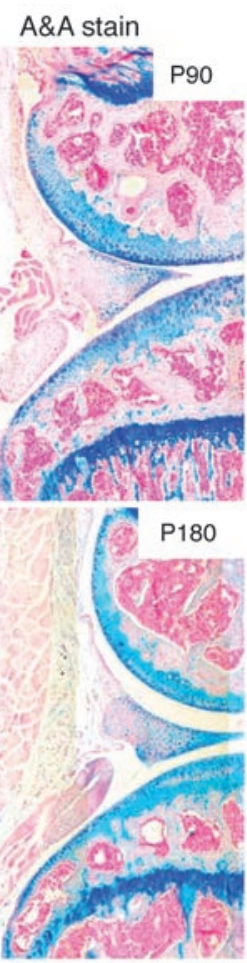

\section{Figure 2}

Lubricin mRNA expression during elbow joint formation and in adult knee joints. (A) Pseudo-colored pictures showing Prg4 mRNA expression (red) and cell nuclei (blue) in the developing mouse elbow joint from E14.5-E17.5. Cavitation between the humerus and ulna begins at E14.5. Gdf5 is still strongly expressed in the presumptive joint mesenchyme, but Prg 4 is not expressed at that time. Prg4 mRNA expression is detected at the forming joint surfaces from E15.5, after cavitation has begun, whereas Gdf5 expression is no longer detected in the joint area. Expression of Prg 4 at the cartilage surfaces and adnexal structures increases further as maturation proceeds. (B) Pseudo-colored pictures showing Prg 4 or Agc1 mRNA expression (red) and cell nuclei (blue) in 3-month-old (P90) and 6 month-old (P180) mouse knee joints. Alizarin red and Alcian blue-stained (A\&A-stained) adjacent sections are included for orientation. Prg4 expression persists throughout adult life at the articular cartilage surface and within the synovium but is not detectable in the growth plate cartilage. Agc1 is expressed in articular and growth plate cartilage.

surface and endochondral growth plates. By 9 months of age, the knee joint space in $\mathrm{Prg}^{-/-}$mice became filled by a noninflammatory, hyperplastic synovium, and the articular cartilage surface was barely recognizable (Figure 4, C and D). Additionally, examination by radiology revealed calcification of structures flanking the ankle joints at 9 months of age (Figure 3, C and D). Histological analysis showed that this abnormal calcification was present in tendon sheaths and osteophytes (Figure 4, E and F). With advancing age, Prg $4^{-/-}$mice had substantial protein deposition on the cartilage surface, and flattened superficial zone chondrocytes were no longer observed (Figure 5, A-F). Synovial hyperplasia was observed in $\operatorname{Prg}^{4^{-/}}$mice by 2 weeks of age and progressed with age (Figure 5, G-L).

Because intimal cell overgrowth of the fibrous pericardium has been observed in human patients with CACP (16), we specifically looked for but did not find evidence of pericardial overgrowth in the mutant mice. Furthermore, no microscopic differences were observed in other major organs, including cardiac muscle, skeletal muscle, lung, intestine, and liver. Brain was not examined.

Synoviocyte hyperplasia in Prg $4^{-/-}$mice is due to increased cell proliferation. $\operatorname{Prg} 4^{-/}$mice exhibited synovial hyperplasia that progressed with age (Figure 5, G-L). This synovial hyperplasia could be due to either decreased rates of synovial cell death or increased rates of synovial cell proliferation in lubricin-deficient mice. We performed TUNEL staining on knee sections of 10-day-old heterozygous or $\mathrm{Prg}^{-/-}$mice to detect apoptotic cells within the synovium. We did not observe TUNEL-positive cells within the synovium of either the heterozygous mice or the lubricin-deficient mice (Supplemental Figure 1; supplemental material available online with this article; doi:10.1172/JCI200522263DS1), which indicated that there were no gross differences in rates of apoptosis. To assess rates of cell proliferation, we also stained knee sections for proliferating cell nuclear antigen (PCNA) (Figure 6, A-I), and found increased numbers of proliferating cells in the lubricin-deficient mice. BrdU incorporation experiments performed on 2.5-week-old, 2.5-month-old, and 7-month-old mice confirmed these observations. The percent of BrdU-positive cells was consistently higher within the synovium of $\operatorname{Prg} 4^{-1-}$ mice than that of heterozygous controls (Supplemental Figure 2).

Recombinant lubricin inhibits synoviocyte growth in vitro via an adhesion-dependent mechanism. To determine whether the synoviocyte hyperplasia that occurs in $\mathrm{Prg}^{-/-}$mice is intrinsic to the synoviocyte, an indirect consequence of pathology within the joint, or a direct result of lubricin deficiency, we cultured synoviocytes from 4-month-old $\mathrm{Prg}^{4^{-/}}$and wild-type mice ex vivo. Wild-type synoviocytes could be passaged no more than twice before their growth in tissue culture ceased. In contrast, $\operatorname{Prg} 4^{-/-}$synoviocytes could be passaged numerous times without a significant alteration in their doubling time or growth potential. This suggested either 


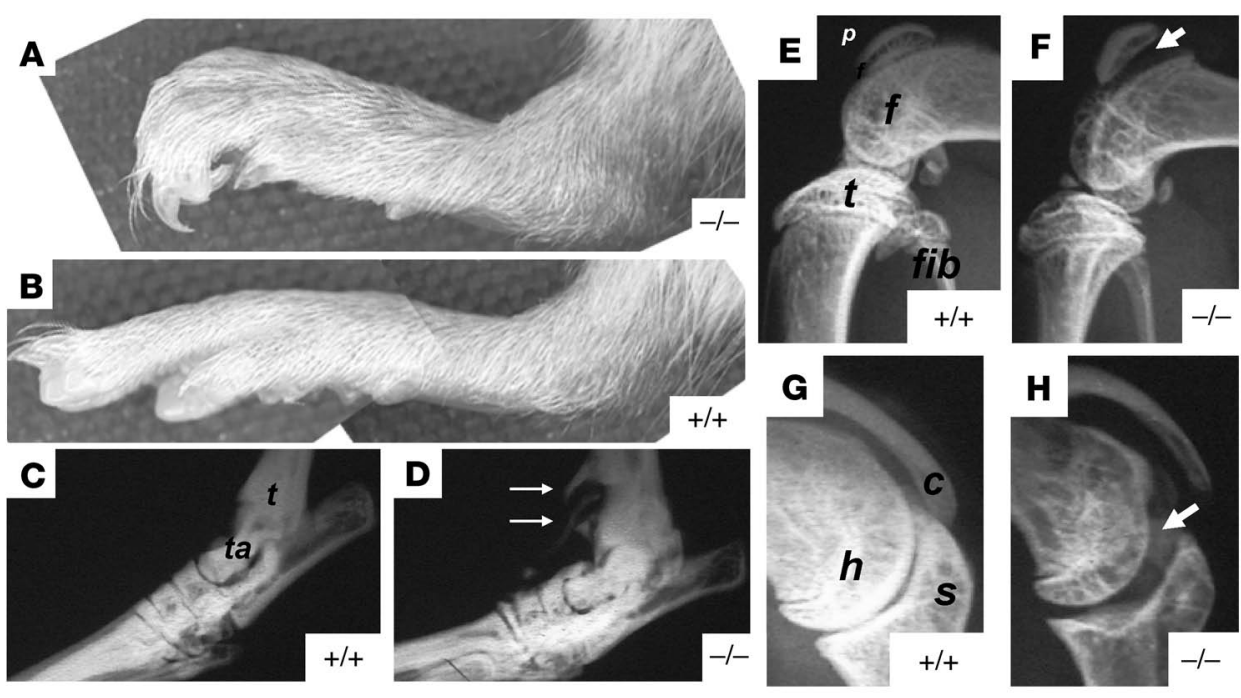

Figure 3

Clinical appearance and radiographic changes in $\mathrm{Prg}^{-/-}$mice. Photograph of the hind paws of 6-monthold $\operatorname{Prg}^{---}$(A) and wild-type (B) mice. Note the curved digits in the mutant mouse and the swelling at the ankle joint. (C and D) Radiograph of the ankle joint of 9-month-old wild-type and Prg $4^{-1-}$ mice, respectively. The structures corresponding to the tibia (t) and talus (ta) are indicated. Note the calcification of structures adjacent to the ankle (white arrows). (E) Lateral knee x-ray of a 4-month-old wild-type mouse. The structures corresponding to the patella (p), femoral condyle (f), tibial plateau (t), and fibula (fib) are indicated. (F) Lateral knee x-ray of a 4-month-old Prg $4^{-/-}$mouse. Note the increased joint space between the patella and femur (arrowheads) and osteopenia of the patella, femoral condyles, and tibial plateau. (G) Shoulder x-ray of a 4-month-old wild-type mouse. The structures corresponding to the humeral head (h), glenoid fossa of the scapula (s), and lateral portion of the clavicle (c) are indicated. (H) Shoulder $\mathrm{x}$-ray of a 4-month old $\mathrm{Prg}^{-/-}$mouse. Note the increased joint space between the humerus and scapula (arrowheads) and the osteopenia of the humeral head.

that mutant mouse synoviocytes acquired genetic (or epigenetic) changes that caused their excessive growth ex vivo or that their excessive growth resulted from an absence of lubricin.

To distinguish between these 2 possibilities, we assessed mutant mouse synoviocyte growth in the presence of conditioned medium that contained recombinant lubricin. $\operatorname{Prg} 4^{-/-}$synoviocytes were trypsinized and reconstituted in lubricin growth medium or in control growth medium. $\mathrm{Prg} 4^{-/-}$synoviocytes that were reconstituted in lubricin growth medium did not adhere to the tissue culture plates and did not divide, whereas cells plated in control growth medium adhered well and grew well (Supplemental Figure 3, A-C). Even after 48 hours, few cells reconstituted in lubricin growth medium had adhered to the dish. When surfaces were pretreated with growth medium, which reduced the amount of lubricin that adhered to the tissue culture plastic (Supplemental Figure 3, D-F) so that cells could adhere to the plates, then the presence of lubricin in the culture medium did not inhibit cell growth. This indicates that lubricin needs to block cell adhesion to affect growth.

Purified human lubricin inhibits adhesion-dependent cell growth. Prg $4^{-1}$ synoviocytes were permitted to adhere overnight in growth medium or serum-free medium. The medium was then removed and replaced with growth medium containing $60 \mu \mathrm{g} / \mathrm{ml}$ of purified human lubricin or growth medium alone. Cells plated in growth medium and then cultured for 5 days in growth medium containing purified lubricin exhibited no significant reduction in growth compared with cells that were similarly plated and then cultured in growth medium alone (Figure 7A). In contrast, cells plated in serum-free medium and then cultured in growth medium containing purified human ally, synoviocytes that were able to grow well on the untreated portion of the dish were unable to grow onto the portion of the dish that had been pretreated with lubricin (Figure 7, D and E). Taken together, these results indicate that lubricin inhibits cell proliferation by an adhesion-dependent mechanism.

The secondary or higher-order structure of lubricin is necessary to inbibit cell adhesion. $\operatorname{Prg}^{-/-}$synoviocytes were unable to attach and proliferate on plastic that had been precoated with lubricin medium (Figure 7D). This inhibition of adhesion was observed not only for synoviocytes but for other adhesion-dependent cell lines such as 293 and COS-7 cells, which do not express lubricin (data not shown). To determine whether the presence of the negatively charged mucinlike domain was sufficient to inhibit adhesion, or whether the protein's globular amino- or carboxy-domains were also important for this effect, we tested whether denatured lubricin (which would disrupt the globular but not the mucin-like domains) could also inhibit adhesion. We did this by precoating tissue culture dishes with lubricin medium in which the protein disulfide bonds had been reduced by DTT or the protein tertiary structure had been heat denatured at $85^{\circ} \mathrm{C}$ for 15 minutes. Reduction with DTT and heat denaturation did not decrease lubricin's solubility or size, as assessed by Western blot analysis (data not shown). Additionally, DTT reduction (Figure 8E) or heat denaturation (Figure 8F) did not inhibit lubricin's ability to adhere to tissue culture plastic. In each instance, lubricin-containing conditioned medium was no longer able to prevent cell adhesion, which indicated that the protein's overall structure, and not just the mucin-like domain, was essential for this biologic activity (Figure 8, A-C). 

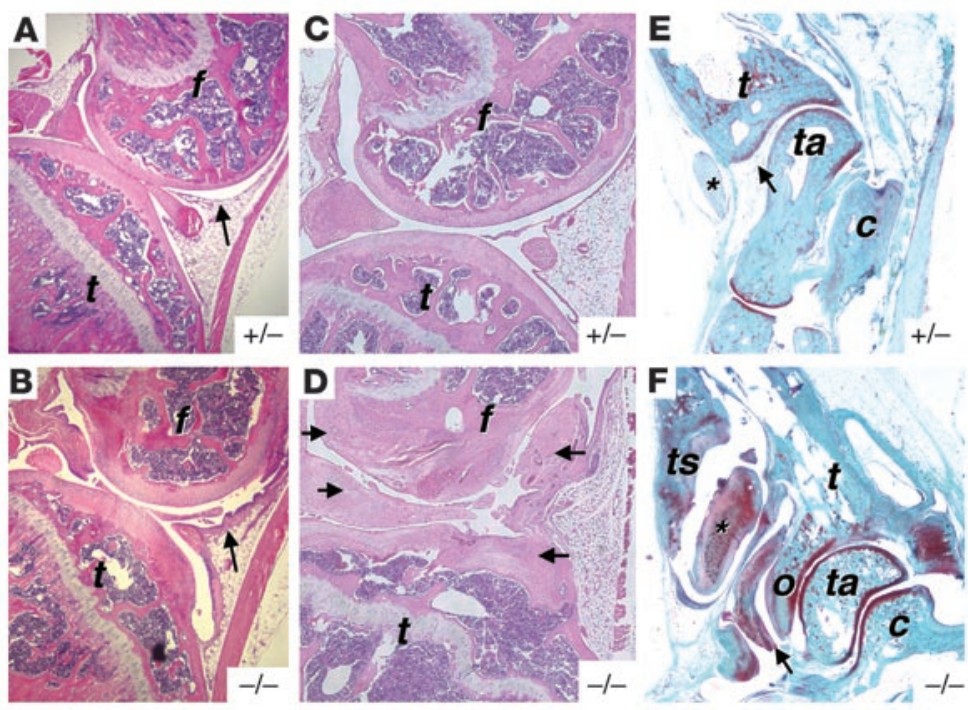

Figure 4

Histologic and radiographic changes in $\mathrm{Prg}^{4^{-/}}$mice. (A) H\& E-stained sagittal section through the knee joint of a 2-month-old heterozygous mouse (heterozygous mice and wild-type mice have similar histology). Femur (f), tibia (t), and synovium (arrow) are noted. (B) Similar section from a 2-month-old Prg $4^{-/-}$ mouse (magnification in $\mathbf{A}$ and $\mathbf{B}, \times 100$ ). Note thickening of the synovium and irregularity and thickening of the cartilage surface. Also note the irregularity in the tibial growth plate. The irregularity of the growth plate is most likely due to a secondary consequence of pathology within the joint, since lubricin is not normally expressed by growth plate chondrocytes (Figure 2B). (C and D) H\&E-stained sagittal sections through the knee joint of 9-month-old heterozygous and $\mathrm{Prg} 4^{-/}$ mice, respectively (magnification, $\times 100$ ). Note the preservation of recognizable structures in the heterozygous joint in contrast to the mutant joint. Also note the hyperplastic synovium throughout the joint. (arrows). (E and F) Safranin-Oand fast green-stained sagittal sections through the ankle joint of 7-month-old heterozygous and $\mathrm{Prg}^{-/-}$mice, respectively (magnification, $\times 25$ ). Tibia, talus, calcaneus (c), tibial osteophyte (o), tibialis anterior tendon $\left(^{*}\right)$ and tendon sheath (ts), and synovium (arrow) are labeled. Note the abnormal appearance of the tendon, tendon sheath, synovium, and osteophyte in the $\mathrm{Prg}^{-/-}$mouse.

\section{Discussion}

The in situ hybridization study of lubricin mRNA expression during joint morphogenesis and the histologic study of $\mathrm{Prg}^{-/-}$mouse joints indicate that lubricin is not required for joint morphogenesis. Articulating joints develop from mesenchymal cell condensations, which initially appear homogeneous but subsequently form trilaminar structures at sites of future joints (25). Cells in the middle layer of these structures undergo apoptosis, leading to formation of joint cavities. Cells in the outer layers differentiate to form the articular cartilage surfaces. Adjacent to the initial mesenchymal cell condensation, new cells migrate and differentiate to form adnexal structures, such as ligaments and synovium. Lubricin mRNA is not detected until after joint cavitation has begun (Figure 2). That lubricin expression increases as the joint matures suggests that it has a functional rather than a morphogenic role. This observation is supported by the normal appearance under light microscopy of the articulating joints in mutant mice in the newborn period and by the clinical observation that patients with CACP appear to have normal joints at birth (16). Our study does not preclude a role for lubricin during the formation of a specific joint structure, the lamina splendens (26). This specialized acellular surface layer of articular cartilage is hypothesized to be involved in boundary lubrication at the joint surface. Lubricin is likely to be among the component molecules of the lamina splendens. However, it is not yet known how the lamina splendens forms and when lubricin is incorporated into its structure.

Clinical, radiologic, and histologic studies of $\mathrm{Prg}^{-/-}$ mice indicate that lubricin is essential for long-term joint homeostasis. Prg $4^{-/-}$mice lose their superficial zone chondrocytes and develop hyperplastic synovia (Figure 5). The latter ultimately grow to invade and destroy adjacent cartilage surfaces. The precise mechanism by which the normal expression of lubricin protects against these 2 pathologic changes is not known. In the case of the superficial chondrocytes, 2 non-mutually exclusive mechanisms could be responsible: (a) direct damage to the cells because of increased friction and (b) restricted access of these cells to nutrients or vital growth factors because of the abnormal protein deposition (Figure 5). Synovial fluid contains growth factors that affect chondrocyte growth (27). Deeper chondrocytes may initially be protected because of their surrounding matrix and lower metabolic rate. However, even these cells eventually disappear, and their surrounding matrix deteriorates in $\mathrm{Prg}^{4^{-/-}}$as they age. Alterations of the cartilage surface are among the earliest changes observed in common osteoarthritis (28), which suggests that acquired alterations of lubricin function may contribute to the pathogenesis of this disease.

The morphologic changes and abnormal calcification of tendon sheaths that surround the ankle joint in $\mathrm{Prg}^{-/-}$ mice are consistent with the previously suggested role for lubricin in providing lubrication and cytoprotection in bovine tendon (29). Presumably, the absence of lubricin within the tendon sheath results in decreased lubrication that leads to tissue damage, matrix remodeling, and dystrophic calcification. These pathological changes within the tendon and tendon sheath likely result in the camptodactyly observed in CACP patients and $\mathrm{Prg}^{-/-}$mice.

The synovial overgrowth that occurs in $\mathrm{Prg}^{-/-}$mice and in patients with CACP is intriguing. $\mathrm{Prg}^{-/-}$synoviocytes have growth characteristics ex vivo that are different from wildtype synoviocytes, which indicates that the cells experience genetic (or epigenetic) changes, as have been described in "activated" synoviocytes recovered from patients with rheumatoid arthritis (30, 31 ), or that their growth is controlled by lubricin. Our studies support the latter explanation, since we have shown that lubricin can inhibit the adhesion-dependent cell growth of $\operatorname{Prg} 4^{-/-}$synoviocytes in tissue culture. Our studies also suggest that it is the absence of lubricin from cartilage surfaces that contributes to the ability of these hyperplastic synoviocytes to grow on and ultimately invade the cartilage of $\mathrm{Prg}^{-/-}$mice. This role for lubricin is consistent with the observation that fibroblast cells cannot adhere to normal cartilage surfaces (32). Other mucins also have antiadhesive properties (33). In the case of bovine salivary mucin, antiadhesion is mediated by steric hindrance caused by the carbohydrate residues (33). However, steric hindrance of the mucin-like domain alone does not account for the antiadhesive property of lubricin, since protein denaturation by heating or adding reducing agents impaired its antiadhesive properties. This implies that lubricin's amino- and carboxy-domains are necessary for its in vitro ability to prevent adhesion-dependent cell growth. These domains also appear to be essential to lubricin function in vivo, since reduction and alkyla- 

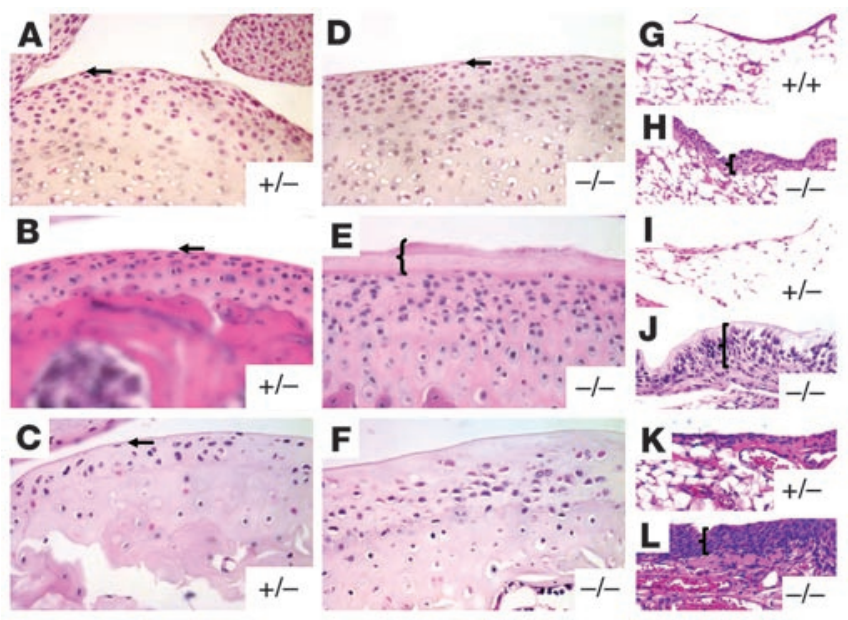

tion of lubricin decrease the protein's ability to bind bovine articular cartilage (34). Interestingly, the ability of lubricin to act as an in vitro boundary lubricant is also lost after reduction and alkylation (34) and chymotrypsin digestion (35), which indicates that this biologic property also requires the protein's globular domains. In our experiments we used a Prg 4 mRNA splice form that lacks exons 2, 4, and 5, and is the common Prg4 mRNA species expressed by synoviocytes, to produce a recombinant form of lubricin. However, we also used purified human lubricin from synovial fluid and found it had the same effect as the recombinant mouse protein in vitro. Other splice variants and post-translationally modified products of PRG4 exist (e.g., SZP, MSF, HAPO), and our results do not preclude the possibility that they have biologic activities that overlap with or are different from the protein isoforms used in these experiments.

The ultimate invasion of the cartilage surface by synoviocytes in $\mathrm{Prg}^{-/-}$mice is reminiscent of the cartilage invasion of rheumatoid arthritic joints by the inflammatory pannus. Therefore, it is reasonable to speculate that inflammation-induced changes in lubricin that occur in the joints of patients with rheumatoid arthritis, such as its enzymatic degradation by leukocyte proteases, serve to hasten joint destruction in this disease.

Lubricin deficiency in mice recapitulates many of the features of human CACP, such as camptodactyly, synovial hyperplasia, and joint failure. Importantly, study of the mutant mice has provided new insights about the protein's role at the cartilage surface. Our results suggest that lubricin is needed to prevent protein deposition onto cartilage from synovial fluid, control adhesion-depen-

\section{Figure 6}

PCNA staining within the knee synovium of 10-day-old heterozygous and $\mathrm{Prg}^{-/-}$mice. Images of sections from heterozygous and mutant mice visualized with DAPI fluorescence for nuclei $(\mathbf{A}, \mathbf{B}$, and $\mathbf{C})$ and PCNA for proliferating cells ( $\mathbf{D}, \mathbf{E}$, and $\mathbf{F}$ ) were merged to visualize dividing cells and determine their number relative to the total cell number $(\mathbf{G}, \mathbf{H}$, and $\mathbf{I})$. Note the synovial hyperplasia present in the 10-dayold $\mathrm{Prg}^{-1-}$ mouse (B) compared with the 10-day-old heterozygous mouse $(\mathbf{A})$ (magnification, $\times 200$ ). Also note the increased PCNA staining within the synovium of the $\mathrm{Prg}^{4^{--}}$mouse ( $\mathrm{H}$ and $\mathbf{I}$ ) compared with the heterozygote $(\mathbf{G})$. I shows the synovium at the suprapatellar reflection and $\mathbf{G}$ and $\mathbf{H}$, the anterior synovium (the region indicated by arrows in Figure 4, A and B).

\section{Figure 5}

Histologic changes in the articular cartilage and synovium of $\mathrm{Prg}^{-/-}$ mice. H\&E-stained sagittal section through the tibia of 7-day-old heterozygous (A) and $\mathrm{Prg}^{-/-}$(D) mice, 2-month-old heterozygous (B) and $\mathrm{Prg}^{-/-}$(E) mice, and 9-month-old heterozygous (C) and $\mathrm{Prg} 4^{-/-}$ (F) mice (magnification in $\mathbf{A}-\mathbf{F}, \times 400$ ). Note that flattened superficial zone chondrocytes are present in both the heterozygous and $\mathrm{Prg}^{-{ }^{--}}$cartilage of the 7-day-old mice (arrows) (A and D). Flattened superficial zone chondrocytes are present in both the 2-month old and 9-month old (B and $\mathbf{C}$ ) heterozygous mice (arrow) but are lost in the 2-month-old and 9-month-old Prg4-/- mice (E and F). Also note the presence of a thick layer of weakly stained material at the cartilage surface (bracket) (E). (G-L) H\&E-stained section of knee synovium from 15-day-old wild-type $(\mathbf{G})$ and $\operatorname{Prg}^{-/-}(\mathbf{H})$ mice (magnification, $\times 400$ ), 2-month-old heterozygous (I) and $\mathrm{Prg}^{-{ }^{--}}$(J) mice (magnification, $\times 400$ ), and 6-month-old heterozygous (K) and $\mathrm{Prg}^{-/-}$(L) mice (magnification, $\times 200$ ). Note the progressive hyperplasia and thickening (brackets) of the intimal and subintimal layers in the $\operatorname{Prg}^{-/-}$mice $(\mathbf{H}, \mathbf{J}$, and $\mathbf{L})$.

dent synovial growth, and inhibit the adhesion of synovial cells to the cartilage surface.

\section{Methods}

In situ bybridization of lubricin mRNA. RNA in situ hybridization was performed on paraffin-embedded sections using $\left[{ }^{35} \mathrm{~S}\right]$-labeled antisense probes as previously described (36). Limbs from older animals were decalcified prior to embedding and sectioning. We took photomicrographs under dark-field exposure using a red filter for RNA signals and blue fluorescence for nuclei stained with the Hoechst 33258 dye. The Prg 4 probe was a 552-bp fragment (nucleotides 1,919-2,470; A in the ATG methionine initiation codon corresponds to nucleotide 1) of the mouse cDNA sequence (37). The Gdf5 probe, a 1150-bp fragment of the mouse gene, was a gift from F. Luyten (University of Leuven, Leuven, Belgium). The Agc1 probe, a 474-bp fragment (RT-PCR product) corresponding to nucleotides 1,179-1,652 of the mouse Agc1 sequence, was a gift from E. Vuorio (University of Turku, Turku, Finland).

Creation of Prg $4^{-/-}$mice. A mutant Prg4 allele was created by homologous recombination in $129 \mathrm{~Sv} / \mathrm{Ev}$-derived embryonic stem cells (Figure 1B). Targeting resulted in the replacement of $\operatorname{Prg} 4$ exon 6 with $\operatorname{lac} Z$ and neo, which was confirmed by Southern blot analysis. Germline transmission of the targeted allele was also confirmed by Southern blot analysis. We subsequently developed a PCR-based assay to genotype mice. For the PCR-
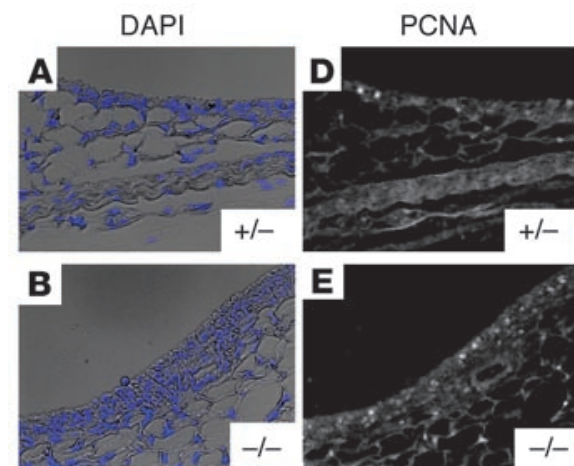

E

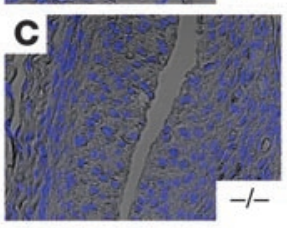

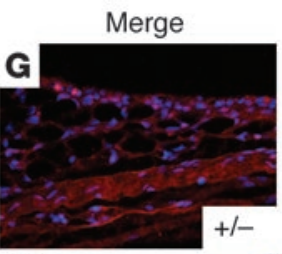
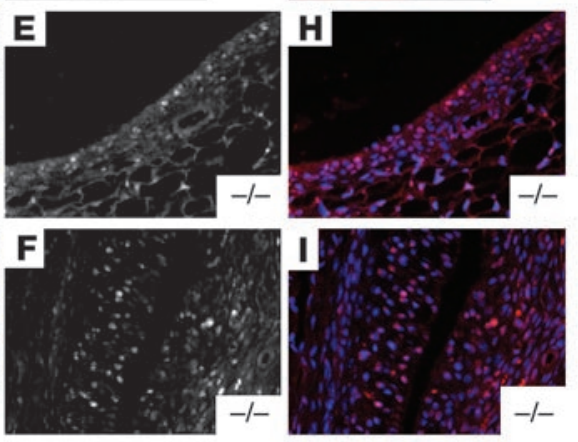

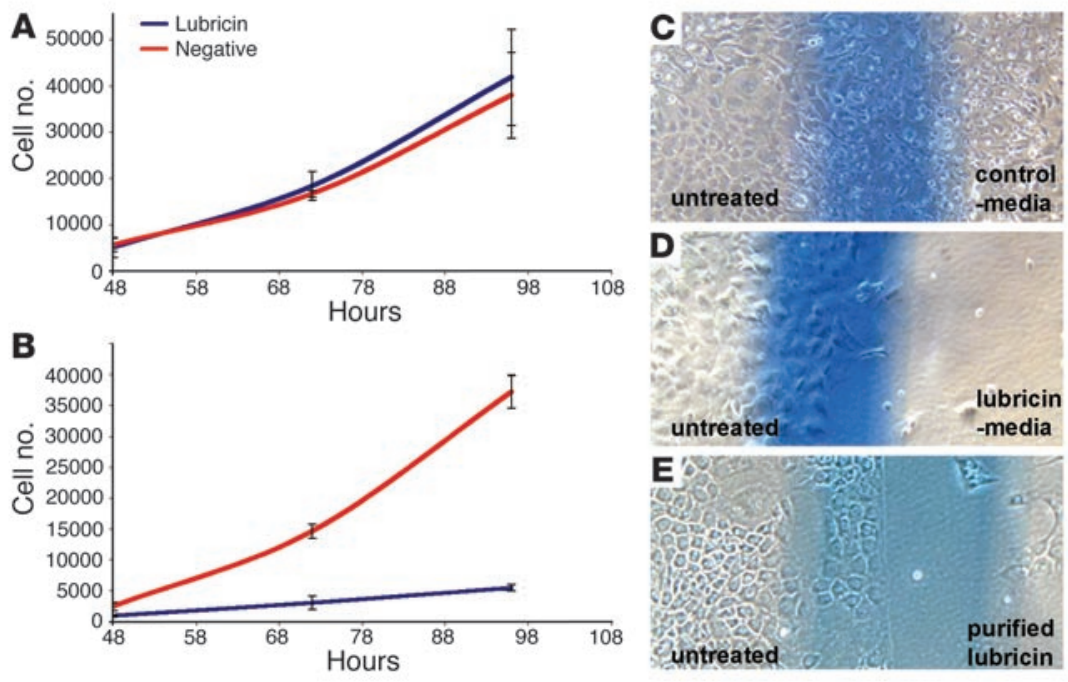

\section{Figure 7}

Effect of purified human lubricin on the in vitro growth of $P r g 4^{-/-}$synoviocytes. (A) Growth curves of adherent $\mathrm{Prg}^{-/-}$synoviocytes that were plated overnight in serum-containing media and then switched to growth media (red) or growth media with $60 \mu \mathrm{g} / \mathrm{ml}$ of purified lubricin (blue). Total cell number ( \pm 1 SEM) was determined 48 hours after addition of growth media or growth media with $60 \mu \mathrm{g} / \mathrm{ml}$ of purified lubricin and every 24 hours thereafter. No significant difference in growth was observed between the 2 groups. (B) Growth curves of adherent $\operatorname{Prg}^{-/-}$synoviocytes that were plated overnight in serum-free media and then switched to growth media (red) or growth media with $60 \mu \mathrm{g} / \mathrm{ml}$ of purified lubricin (blue). Total cell number ( $\pm 1 \mathrm{SE}$ ) was determined 48 hours after addition of growth media or growth media with $60 \mu \mathrm{g} / \mathrm{ml}$ of purified lubricin and every 24 hours thereafter. When plates were not pre-exposed to serum-containing media, Prg $4^{-/-}$synoviocyte growth was significantly inhibited by growth media supplemented with $60 \mu \mathrm{g} / \mathrm{ml}$ of purified lubricin. (C-E) Prg $4^{-/-}$synoviocyte growth on tissue culture plates that were pretreated with control media, lubricin media, or $60 \mu \mathrm{g} / \mathrm{ml}$ of purified lubricin, respectively. Portions of tissue culture plates (to the right of the blue line) were incubated with control media, lubricin media, or $60 \mu \mathrm{g} / \mathrm{ml}$ of purified lubricin overnight at $37^{\circ} \mathrm{C}$. After washing off the media with several changes of PBS, we added $\mathrm{Prg}^{-/}$synoviocytes to the culture dishes and allowed them to proliferate in growth media for 7 days. Note that few synoviocytes were able to adhere to the lubricin-media or purified lubricin treated plates (magnification, $\times 100$ ). Also note that synoviocytes on the untreated portion of the plate did not proliferate onto the lubricin-treated portion.

based genotype assay, a Prg4 forward primer, Prg4F (5'-GGACAACACTGAATACTATAG) that recognizes a sequence within the fifth intron of the Prg 4 gene, and a Prg4 reverse primer, Prg4R (5'-TTGCAGTAGTCTCTTTCGTTTCA) that recognizes a sequence within the sixth exon of the Prg4 gene, was used to amplify by PCR a 400-bp fragment that corresponded to the wild-type allele. Alternatively, the Prg4F primer and a lac $Z$ reverse primer $\left(5^{\prime}\right.$-CCATGCTCCCCACTTTGCGT) that recognizes the lac $Z$ sequence within the mutant allele, were used to amplify by PCR a 400-bp fragment that corresponded to the mutant allele. Genomic DNA was collected from mouse ear-punches and PCR was performed with either primer pair listed above to identify wild-type, heterozygous, or knockout animals. PCR conditions were as follows: 1 cycle at $95^{\circ} \mathrm{C}$ for 3 minutes, 39 cycles at $95^{\circ} \mathrm{C}$ for 30 seconds, $55^{\circ} \mathrm{C}$ for 45 seconds, $72^{\circ} \mathrm{C}$ for 1 minute, and 1 cycle at $72^{\circ} \mathrm{C}$ for 10 minutes.

Mutant mice were maintained on a $129 \mathrm{~Sv} / \mathrm{Ev}$ genetic background. All procedures for mouse research were approved by the Institutional Animal Care and Use Committee of Case Western Reserve University.

Clinical, radiologic, and histologic characterization of wild-type and Prg $4^{-/-}$mice. Mice were examined regularly for symptoms or signs of joint disease or discomfort. After mice were sacrificed by $\mathrm{CO}_{2}$ asphyxiation, limbs were removed from the axial skeleton and radiographed at 30 kilovolt peak for 1.5 minutes using a Faxitron model 8050-010 (Faxitron X-ray Corp.) on Kodak X-OMAT AR Scientific Imaging film (Eastman Kodak Co.). Images were captured with an Optronics LX-450 (Optronics Inc.) camera attached to a Leica MZFLIII microscope (Leica Microsystems Inc.). Knee joints were fixed in 10\% formalin for 48 hours at $4{ }^{\circ} \mathrm{C}$, decalcified, and embedded in paraffin. We collected serial sagittal sections $(5 \mu \mathrm{m})$, beginning laterally and moving medially across the entire joint, on Fisherbrand Superfrost Plus slides (Fisher Scientific International) and used them for histochemical staining.

TUNEL and immunohistochemical analysis of heterozygous mice, Prg $4^{-/}$mice, and cultured Prg $4^{-/-}$synoviocytes. Mice were sacrificed and knee joints collected, fixed, decalcified, embedded in paraffin, and sectioned as described above. Sections were dewaxed and rehydrated in a series of graded alcohols prior to TUNEL staining or immunohistochemistry. For TUNEL staining, the In Situ Cell Death Detection Kit, TMR red (Roche Diagnostics Corp.) was used according to the manufacturer's specifications. As a positive control, one sample was incubated with $300 \mathrm{U} / \mathrm{ml}$ of Dnase I in $50 \mathrm{mM}$ Tris- $\mathrm{HCl}, 1 \mathrm{mg} / \mathrm{ml}$ BSA, pH 7.5, to induce DNA double-strand breaks. For PCNA staining, sections were blocked for 20 minutes in blocking buffer ( $1 \%$ donkey serum/0.1\% Triton in PBS). A polyclonal goat anti-PCNA (C-20) antibody (Santa Cruz Biotechnology Inc.) was diluted 1:100 in blocking buffer and incubated with each sample overnight at $4^{\circ} \mathrm{C}$. After incubation, samples were washed twice in PBS and once in blocking buffer. A polyclonal donkey anti-goat Alexa Fluor 594 (Invitrogen Corp.) secondary antibody was diluted 1:400 in blocking buffer and incubated with each sample for 30 minutes. Samples were washed twice in PBS and once in blocking buffer, counterstained with DAPI, and analyzed by fluorescence microscopy. For $\operatorname{Prg} 4^{-/-}$synoviocyte proliferation experiments, cells were fixed for 10 minutes in a 50:50 mixture of methanol and acetone. PCNA staining was performed as described above, except each sample was incubated with a 1:100 dilution of polyclonal PCNA antibody for 1 hour at room temperature.

BrdU incorporation and immunohistochemical detection. At 2.5 weeks, 2.5 months, and 7 months of age, heterozygous and $\mathrm{Prg} 4^{-/-}$mice were given intraperitoneal injections of $1 \mathrm{ml} / 100 \mathrm{~g}$ BrdU labeling reagent (Zymed Laboratories Inc.) and sacrificed 3 hours later. Knee joints were fixed in $10 \%$ formalin for 48 hours at $4{ }^{\circ} \mathrm{C}$, decalcified, and embedded in paraffin. Serial sagittal sections $(5 \mu \mathrm{m})$ traversing the entire joint from the lateral to medial side were collected on Fisherbrand Superfrost Plus slides and used for histochemical staining. A BrdU staining kit (Zymed Laboratories Inc.) was used according to the manufacturer's specifications to stain for BrdU-positive cells within the synovium of all treated animals. The percent BrdU-positive cells was determined by dividing the number of BrdU-positive synovial cells by the total number of synovial cells that were counted in multiple sections.

Generation of recombinant lubricin-containing conditioned medium and control conditioned medium. All cell cultures were performed at $37^{\circ} \mathrm{C}$ in an atmosphere with $5 \% \mathrm{CO}_{2}$. A pME18S vector, which expresses a common splice variant of murine lubricin (Prg4) that lacks exons 2, 4, and 5 (37), was generously provided by Shiro Ikegawa (University of Tokyo, Tokyo, Japan). COS-7 cells were cultured in growth medium (DMEM with 10\% FBS, 100 

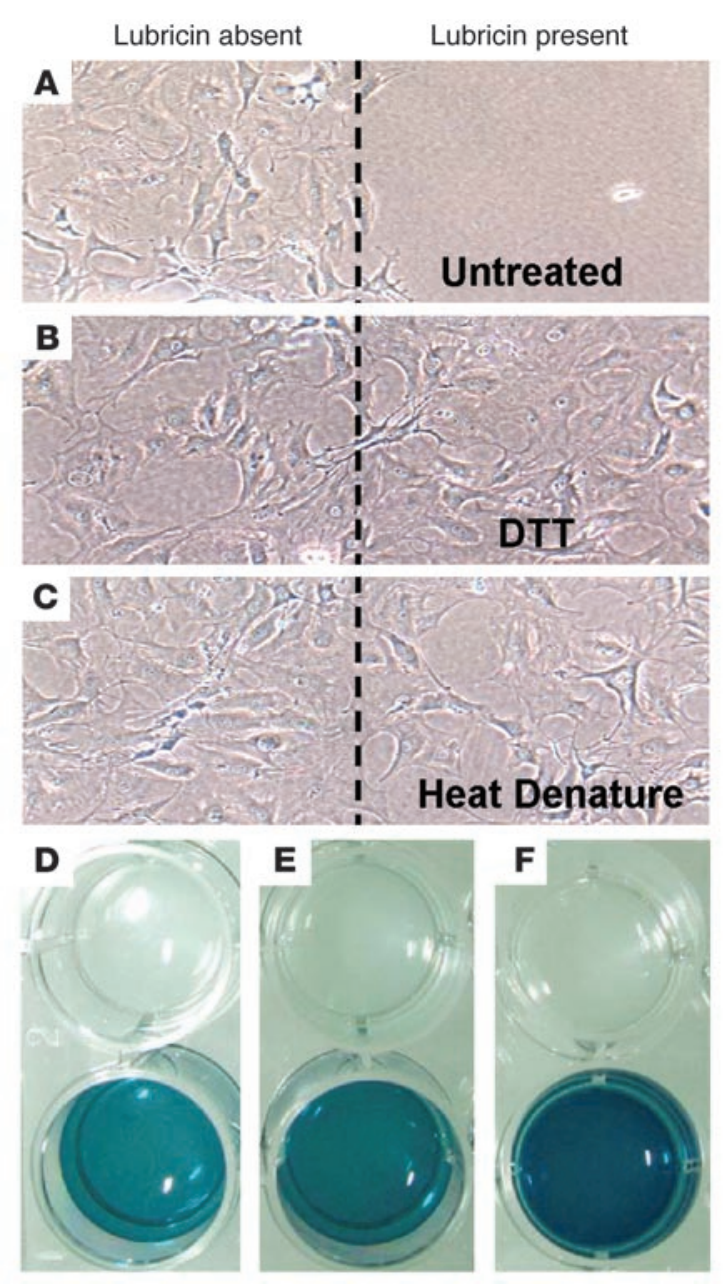

$\mathrm{U} / \mathrm{ml}$ penicillin, $100 \mu \mathrm{g} / \mathrm{ml}$ streptomycin, and $250 \mathrm{ng} / \mathrm{ml}$ amphotericin B; Invitrogen Corp.). Cells were grown in $100-\mathrm{mm}$ dishes to approximately $80 \%$ confluence and transfected with $40 \mu$ l of FuGENE 6 (Roche Diagnostics Corp.) and $5 \mu \mathrm{g}$ of plasmid DNA in Opti-MEM I (Invitrogen Corp.) according to the manufacturer's recommendations. Recombinant protein was collected in 2 different types of media. For cell proliferation studies, Prg4-transfected COS-7 cells and those treated with FuGENE6 only were maintained in growth medium for 24 hours and then switched to $10 \mathrm{ml}$ of fresh growth medium, yielding lubricin growth medium and control growth medium, respectively. For studies that involved pretreatment of tissue culture plastic, transfected COS-7 cells were maintained in growth medium for 24 hours and then switched to $10 \mathrm{ml}$ of serum-free DMEM/plate, which yielded lubricin medium and control medium, respectively. After 24 hours, conditioned medium and cell lysate were harvested and aliquots were analyzed for the presence of recombinant lubricin by Western blot analysis.

Western blot analyses of lubricin in conditioned medium and colorimetric assay of lubricin adhesion to tissue culture plastic. All conditioned media were cleared of cell debris by centrifugation at $1,800 \mathrm{~g}$ for 10 minutes at room temperature. After centrifugation, equal aliquots of medium and $2 \times$ Laemmli loading buffer were mixed and boiled for 5 minutes; $20 \mu 1$ was loaded per lane. Samples were separated by SDS-PAGE under reducing conditions (5\% $\beta$-mercaptoethanol) and transferred onto an Immobilon-P membrane (Millipore Corp.). Lubricin was detected using a sensitive and specific rabbit anti-lubricin polyclonal antibody generated against a polypeptide epitope (FESFERGRECDAQCKKYDK) encoded by exon 3. This epitope

\section{Figure 8}

Effect of reduction and heat denaturation on the ability of lubricin to inhibit Prg4 $4^{-/}$synoviocyte growth. Portions of tissue culture plates (to the right of the dashed lines) were incubated overnight at $37^{\circ} \mathrm{C}$ with untreated (A), DTT-reduced (B), or heat-denatured (C) lubricin media. After washing off the media with several changes of PBS, we added $\mathrm{Prg}^{-/-}$synoviocytes to the culture dishes and allowed them to proliferate in growth media for 7 days. Note that cells were able to proliferate on the portions of the plates that contained reduced or heat-denatured lubricin media but not on untreated lubricin media (magnification, $\times 100)$. (D-F) Immunodetection of lubricin adhesion to tissue culture plastic. Upper wells were incubated overnight at $37^{\circ} \mathrm{C}$ with untreated (D), DTT-reduced $(\mathbf{E})$, or heat-denatured $(\mathbf{F})$ control media. Lower wells were incubated overnight at $37^{\circ} \mathrm{C}$ with untreated (D), DTT-reduced (E), or heat denatured (F) lubricin media. Wells were washed several times with PBS, and we determined lubricin adhesion to the plastic using an anti-lubricin antibody and an HRP-conjugated secondary antibody. Note that lubricin was detected in all 3 lubricin media wells and not in any of the control media wells.

is amino-terminal of the mucin-like domain and present in all lubricin isoforms (35). This antibody specifically recognizes lubricin protein (Supplemental Figure 2, A and B). Blots were blocked for 1 hour with $5 \%$ nonfat dry milk in TBS (150 mM NaCl, $20 \mathrm{mM}$ Tris, $\mathrm{pH} 7.5)$ and then incubated with a $1: 500$ dilution of anti-lubricin antibody in $2.5 \%$ nonfat dry milk, TBS, $0.05 \%$ Tween $20, \mathrm{pH} 7.5$ ) for 1 hour. After 3 washes with TBST (150 $\mathrm{mM} \mathrm{NaCl}, 20 \mathrm{mM}$ Tris, $0.05 \%$ Tween $20, \mathrm{pH} 7.5$ ), blots were incubated with a 1:5,000 dilution of HRP secondary antibody (goat anti-rabbit; Santa Cruz Biotechnology Inc.) in antibody buffer for 1 hour and then washed again 3 times with TBST. Immunoreactive proteins were detected with the ECL Plus chemiluminescent detection system (Amersham Biosciences). We quantified recombinant lubricin concentration in conditioned medium by comparing these band intensities to band intensities of lanes containing known amounts of purified murine lubricin. Control growth medium and control medium contained no immunodetectable lubricin. Lubricin growth medium and lubricin medium contained approximately $80 \mu \mathrm{g} / \mathrm{ml}$ of recombinant lubricin. This latter concentration is similar to the concentration present in bovine synovial fluid (10) and the concentration that replicates synovial fluid's lubricating properties in vitro (7).

In order to determine the adhesion of lubricin to tissue culture plastic, we incubated lubricin growth medium or control growth medium on tissue culture plates as described below. Each sample was removed, and the plate was washed 3 times with PBS. Samples were blocked for 1 hour with $5 \%$ nonfat dry milk in TBS and then incubated with a 1:100 dilution of anti-lubricin antibody in antibody buffer. After 3 washes with TBST, blots were incubated with a 1:2,500 dilution of HRP secondary antibody (goat anti-rabbit; Santa Cruz Biotechnology Inc.) in antibody buffer for 1 hour and then washed again 3 times with TBST. Immunoreactive proteins were detected with the Horseradish Peroxidase Substrate Kit (Bio-Rad Laboratories). To differentiate between reduced lubricin adhesion to tissue culture plastic that was pretreated with serum-containing medium and masking of the epitope by serum proteins, adherent proteins were recovered from the dishes under reducing conditions using $100 \mu \mathrm{l}$ of $1 \times$ SDS-PAGE sample buffer and then analyzed by Western blot with the anti-lubricin antibody after reducing SDS-PAGE.

Purification of recombinant murine lubricin. Cells were grown in seventy $100-\mathrm{mm}$ dishes to approximately $80 \%$ confluence and each transfected with $40 \mu \mathrm{l}$ of FuGENE 6 (Roche Diagnostics Corp.) and $5 \mu \mathrm{g}$ of lubricin plasmid DNA (construct described above) in Opti-MEM I according to the manufacturer's recommendations. After 24 hours, transfected COS-7 cells were maintained in growth medium for 24 hours and then switched to $10 \mathrm{ml}$ of serum-free DMEM/plate. After 24 hours, conditioned medium was col- 
lected and pooled (approximately $700 \mathrm{ml}$ ). Cell culture medium was diluted in $50 \mathrm{mM} \mathrm{NaAc}$ buffer, $\mathrm{pH} 5.5$, until the medium reached a $\mathrm{pH}$ of 5.5. The entire sample was loaded on a DEAE column (Whatman International Ltd.) with a settled volume of $300 \mathrm{ml}$ that was equilibrated with $50 \mathrm{mM} \mathrm{NaAc}$ buffer, $\mathrm{pH}$ 5.5. The column was then washed with 5 column volumes of 50 $\mathrm{mM}$ NaAc buffer. The desired material was eluted off the DEAE matrix with $1 \mathrm{M} \mathrm{NaCl}$. Complete Mini Protease Inhibitor Cocktail tablets (Roche Diagnostics Corp.) were added to the eluted fraction. The eluted fraction was then dialyzed against $25 \mathrm{mM}$ phosphate buffer in $0.15 \mathrm{M} \mathrm{NaCl}$ and $0.5 \mathrm{mM}$ $\mathrm{CaCl}_{2}$, $\mathrm{pH} 7.4$ overnight. The DEAE-bound concentrate was loaded on a peanut-agglutinin-agarose affinity column with a settled bed volume of $25 \mathrm{ml}$, equilibrated at room temperature with $25 \mathrm{mM}$ phosphate in $0.15 \mathrm{NaCl}, 0.5$ $\mathrm{mM} \mathrm{CaCl}_{2}$ buffer, $\mathrm{pH}$ 7.4. The column was washed with 5 column volumes of $25 \mathrm{mM}$ phosphate in $0.15 \mathrm{NaCl}, 0.5 \mathrm{mM} \mathrm{CaCl}_{2}$ buffer, $\mathrm{pH}$ 7.4. Protein was eluted with $25 \mathrm{mM}$ phosphate in $0.15 \mathrm{NaCl}, 0.15 \mathrm{M}$ lactose buffer, $\mathrm{pH}$ 7.4. Eluate (containing Complete Mini Protease Inhibitor Cocktail) was dialyzed against PBS overnight. The dialyzed eluate was then dialyzed against $13 \%$ polyethylene glycol in PBS for 7 hours in order to concentrate the sample. Sample concentration was determined using the BCA Protein Assay kit (Pierce Biotechnology Inc.). Purified protein was analyzed by Coomassie staining and by immunoblot assay using the anti-lubricin antibody.

Culture of wild-type and $\mathrm{Prg}^{-/-}$synoviocytes. Four-month-old wild-type and $\mathrm{Prg}^{4 /-}$ mice were sacrificed using $\mathrm{CO}_{2}$, then immersed in $70 \%$ ethanol for 20 seconds. Skin was removed from the hind limbs of each mouse to expose the femorotibial (knee) joints. The patellar tendon was cut transversely immediately above the tibial crest, then the patella and associated tissues were retracted anteriorly. A thin layer of synovium lining the suprapatellar pouch was exposed and placed under tension as the tissues were retracted. This synovium was excised and then immediately placed in serum-free DMEM containing $0.4 \%$ collagenase (wt/vol) (Sigma-Aldrich) for 3 hours. The digested samples were centrifuged and washed 3 times in growth medium. Each sample was then plated in a $60-\mathrm{mm}$ dish with growth medium. Cells were allowed to grow to confluence, removed from the confluent plate by trypsinization, then split equally into three $100-\mathrm{mm}$ culture dishes.

Studies of Prg 4-/- synoviocyte adhesion and growth in the presence or absence of lubricin. Synoviocytes from $\mathrm{Prg}^{4 /-}$ mice were trypsinized and reconstituted in growth medium, lubricin growth medium, or control growth medium. Cells were incubated for 48 hours at $37^{\circ} \mathrm{C}$ in an atmosphere with $5 \% \mathrm{CO}_{2}$ and then assessed by microscopy. For cell proliferation experiments, synoviocytes from $\mathrm{Prg}^{-/-}$mice were plated overnight onto 48 -well plates (0.785 $\mathrm{mm}^{2}$ ) (Costar 3548; Corning Inc.) at equal densities ( $10^{3}$ cells per well) in growth medium or serum-free medium. After 24 hours, the plating medium was removed, plates were washed 3 times with PBS, and either growth medium containing purified human lubricin (purified as described previously; ref. 8) at a concentration of $60 \mu \mathrm{g} / \mathrm{ml}$ or growth medium with PBS (as a control for the volume of purified lubricin added to the experimental group) was added. Cells were allowed to grow for 48 hours and assessed every 24 hours thereafter. Five photomicrographs were taken of each sample, the cells visible in each image were counted, and the averages of the 5 images were taken. In order to determine the total number of cells present on the dish, the size of the region represented in the image was determined using a micrometer. This area was determined to be a certain percentage of the total area of the dish, and the number of cells present in each image was multiplied by this coefficient to determine total cell population on the plate. Each experiment was performed in duplicate, and all values were averaged.

To assess the effect of purified lubricin or recombinant lubricin on synoviocyte adhesion to tissue culture plates, purified human lubricin $(60 \mu \mathrm{g} / \mathrm{ml})$ (9), lubricin medium, or control medium was aliquoted on portions (demarcated on the underside of the culture dishes with a marking pen) of 100-mm polystyrene cell culture dishes (Falcon 35-3003; BD). Each dish was then incubated at $37^{\circ} \mathrm{C}$ in an atmosphere with $5 \% \mathrm{CO}_{2}$ for 24 hours. Following incubation, each plate was washed 3 times with PBS. Prg $4^{-/}$synoviocytes (or COS-7 or 293T cells) were then plated at equal densities on each plate in growth medium for 1 week. Cell adhesion and growth on treated and untreated portions of the plates were assessed microscopically.

In order to demonstrate that lubricin adhered to the portion of the tissue culture plastic to which it had been applied, lubricin-medium or control medium was incubated on a portion of tissue culture plastic (region within the blue circle indicated in Supplemental Figure 3) as described above. Medium was removed, and each plate was washed 3 times with PBS. Samples were blocked, incubated with anti-lubricin antibody, and washed 3 times with TBST as described above. Each sample was then incubated with a 1:2,500 dilution of alkaline phosphatase-conjugated secondary antibody (goat antirabbit; Santa Cruz Biotechnology Inc.) in antibody buffer for 1 hour and then washed again 3 times with TBST. Immunoreactive proteins were detected with nitro blue tetrazolium/5-bromo-4-chloro-3-indolyl phosphatase (NBT/BCIP) as precipitating reagents (Roche Diagnostics Corp.).

To determine whether the secondary or higher-order structure of lubricin was necessary to inhibit synovial cell adhesion, lubricin medium and control medium were either reduced with $100 \mathrm{mM}$ DTT for 4 hours at room temperature or heat denatured at $85^{\circ} \mathrm{C}$ for 15 minutes and then aliquoted onto tissue culture dishes as described above. Each treated sample was also subjected to Western blot analysis to assess the treatment's effect on lubricin solubility and size. Additionally, each sample was analyzed using the anti-lubricin antibody in a colorimetric assay to ensure that each treatment did not inhibit lubricin from adhering to the tissue culture plastic. Cells were then plated at equal densities on each plate in growth medium for one week and assessed microscopically.

Statistical analysis. All statistical analyses were performed using $\chi^{2}$ analysis with 2 degrees of freedom (for fertility studies) or 1 degree of freedom (for BrdU Inc. experiments). $P$ values for significance were set at 0.05 .

\section{Acknowledgments}

The authors thank Pam Schwartzberg and Amy Chen for help in creating the lubricin-deficient mice, Theresa Pizzuto for her histologic expertise, Melanie Rhee for her assistance with microscopic images, and Brian Johnstone for helpful scientific discussions. M.L. Warman is an assistant investigator with the Howard Hughes Medical Institute. This work was also supported by a Clinical Scientist Award in Translational Research from the Burroughs Wellcome Fund and by NIH grant AR050180. D.K. Rhee was supported by NIH grants GM07250, HD07518, and GM08613. J. Marcelino was supported by a postdoctoral fellowship from the Arthritis Foundation and by NIH grant HD07104. P. Smits was supported by a postdoctoral fellowship from the Arthritis Foundation. V. Lefebvre was supported in part by NIH grant AR46249. G.D. Jay was supported by NIH grant K08AG/AR01008 and the McCutchen Foundation.

Received for publication May 26, 2004, and accepted in revised form January 11, 2005.

Address correspondence to: Matthew L. Warman, Case Western Reserve University, 2109 Adelbert Road, BRB-719, Cleveland, Ohio 44106, USA. Phone: (216) 368-4919; E-mail: mlw14@case.edu. Or to: John D. Carpten, Genetic Basis of Human Disease Research Division, Translational Genomics Research Institute, 445 North 5th Street, Phoenix, Arizona 85004, USA. Phone: (602) 343-8819; E-mail: jcarpten@tgen.org.

David K. Rhee and Jose Marcelino contributed equally to this work. 
1. Tudor-Locke, C., and Bassett, D.R., Jr. 2004. How many steps/day are enough? Preliminary pedometer indices for public health. Sports Med. 34:1-8.

2. Mankin, H. 1963. Localisation of tritiated thymidine in articular cartilage of rabbits. III. Mature articular cartilage. J. Bone Joint Surg. 45A:529-540.

3. Hunziker, E.B. 1999. Articular cartilage repair: are the intrinsic biological constraints undermining this process insuperable? Osteoarthritis Cartilage. 7:15-28.

4. Felson, D.T., and Zhang, Y. 1998. An update on the epidemiology of knee and hip osteoarthritis with a view to prevention. Arthritis Rheum. 41:1343-1355.

5. Levick, J. 1984. Blood flow and mass transport in synovial joints. In Handbook of Physiology, Microcirculation. Section 2, Volume IV, Part 2. E. Renkins and C. Michel, editors. American Physiological Society. Bethesda, Maryland, USA. 917-947.

6. Swann, D.A., and Radin, E.L. 1972. The molecular basis of articular lubrication. I. Purification and properties of a lubricating fraction from bovine synovial fluid. J. Biol. Chem. 247:8069-8073.

7. Jay, G.D., Haberstroh, K., and Cha, C.J. 1998. Comparison of the boundary-lubricating ability of bovine synovial fluid, lubricin, and Healon. J. Biomed. Mater. Res. 40:414-418.

8. Jay, G.D. 1992. Characterization of a bovine synovial fluid lubricating factor. I. Chemical, surface activity and lubricating properties. Connect. Tissue Res. 28:71-88.

9. Jay, G.D., Britt, D.E., and Cha, C.J. 2000. Lubricin is a product of megakaryocyte stimulating factor gene expression by human synovial fibroblasts. J. Rheumatol. 27:594-600.

10. Swann, D.A., Silver, F.H., Slayter, H.S., Stafford, W., and Shore, E. 1985. The molecular structure and lubricating activity of lubricin isolated from bovine and human synovial fluids. Biochem. J. 225:195-201.

11. Marcelino, J., et al. 1999. CACP, encoding a secreted proteoglycan, is mutated in camptodactylyarthropathy-coxa vara-pericarditis syndrome. Nat. Genet. 23:319-322.

12. Schumacher, B.L., Hughes, C.E., Kuettner, K.E., Caterson, B., and Aydelotte, M.B. 1999. Immunodetection and partial cDNA sequence of the proteoglycan, superficial zone protein, synthesized by cells lining synovial joints. J. Orthop. Res. 17:110-120.

13. Schumacher, B.L., Block, J.A., Schmid, T.M., Aydelotte, M.B., and Kuettner, K.E. 1994. A novel pro- teoglycan synthesized and secreted by chondrocytes of the superficial zone of articular cartilage. Arch. Biochem. Biophys. 311:144-152.

14. Merberg, D., Fitz, L., and Temple, P. 1993. A comparison of vitronectin and megakaryocyte stimulating factor. In Biology of Vitronectins and their Receptors. K. Preissner, S. Rosenblattt, C. Kost, J. Wegerhoff, and D. Mosher, editors. Elsevier Science Publishers BV. Amsterdam, The Netherlands. 45-54.

15. Liu, Y.J., et al. 2004. Hemangiopoietin, a novel human growth factor for the primitive cells of both hematopoietic and endothelial cell lineages. Blood. 103:4449-4456.

16. Bahabri, S.A., et al. 1998. The camptodactylyarthropathy-coxa vara-pericarditis syndrome: clinical features and genetic mapping to human chromosome 1. Arthritis Rheum. 41:730-735.

17. Deng, G., Curriden, S.A., Hu, G., Czekay, R.P., and Loskutoff, D.J. 2001. Plasminogen activator inhibitor-1 regulates cell adhesion by binding to the somatomedin B domain of vitronectin. J. Cell. Physiol. 189:23-33.

18. Schvartz, I., Seger, D., and Shaltiel, S. 1999. Vitronectin. Int. J. Biochem. Cell Biol. 31:539-544.

19. Seiffert, D., and Smith, J.W. 1997. The cell adhesion domain in plasma vitronectin is cryptic. J. Biol. Chem. 272:13705-13710.

20. Zheng, X., Saunders, T.L., Camper, S.A., Samuelson, L.C., and Ginsburg, D. 1995. Vitronectin is not essential for normal mammalian development and fertility. Proc. Natl. Acad. Sci. U. S. A. 92:12426-12430.

21. Jay, G.D., Harris, D.A., and Cha, C.J. 2001. Boundary lubrication by lubricin is mediated by O-linked beta(1-3)Gal-GalNAc oligosaccharides. Glycoconj. J. 18:807-815.

22. Van Klinken, B.J., Dekker, J., Buller, H.A., and Einerhand, A.W. 1995. Mucin gene structure and expression: protection vs. adhesion. Am. J. Physiol. 269:G613-G627.

23. Simmons, P.J., Levesque, J.P., and Haylock, D.N 2001. Mucin-like molecules as modulators of the survival and proliferation of primitive hematopoietic cells. Ann. N. Y. Acad. Sci. 938:196-206; discussion 206-197.

24. Velcich, A., et al. 2002. Colorectal cancer in mice genetically deficient in the mucin Muc2. Science. 295:1726-1729.

25. Haines, R. 1947. The development of joints. J. Anat.
81:33-54.

26. Guerra, D., et al. 1996. Ultrastructural identification of a membrane-like structure on the surface of normal articular cartilage. J. Submicrosc. Cytol. Pathol. 28:385-393.

27. Skoog, V., Widenfalk, B., Ohlsen, L., and Wasteson, A. 1990. The effect of growth factors and synovial fluid on chondrogenesis in perichondrium. Scand. J. Plast. Reconstr. Surg. Hand Surg. 24:89-95.

28. Fassbender, H. 2002. Pathology and pathobiology of rhewmatic diseases. Springer. Berlin, Germany. 503 pp.

29. Rees, S.G., et al. 2002. Immunolocalisation and expression of proteoglycan 4 (cartilage superficial zone proteoglycan) in tendon. Matrix Biol. 21:593-602.

30. Firestein, G.S. 1996. Invasive fibroblast-like synoviocytes in rheumatoid arthritis. Passive responders or transformed aggressors? Arthritis Rheum. 39:1781-1790.

31. Firestein, G.S., Echeverri, F., Yeo, M., Zvaifler, N.J., and Green, D.R. 1997. Somatic mutations in the p53 tumor suppressor gene in rheumatoid arthritis synovium. Proc. Natl. Acad. Sci. U. S. A. 94:10895-10900

32. Noyori, K., and Jasin, H.E. 1994. Inhibition of human fibroblast adhesion by cartilage surface proteoglycans. Arthritis Rheum. 37:1656-1663.

33. O'Boyle, K.P., Chen, T., and Kozlowski, S. 2000. Mucin inhibition of lymphocyte function does not require specific mucin-ligand interactions. Scand.J. Immunol. 52:46-52.

34. Swann, D.A., Hendren, R.B., Radin, E.L., Sotman, S.L., and Duda, E.A. 1981. The lubricating activity of synovial fluid glycoproteins. Arthritis Rheum. 24:22-30.

35. Jay, G.D., Tantravahi, U., Britt, D.E., Barrach, H.J., and Cha, C.J. 2001. Homology of lubricin and superficial zone protein (SZP): products of megakaryocyte stimulating factor (MSF) gene expression by human synovial fibroblasts and articular chondrocytes localized to chromosome 1q25. J. Orthop. Res. 19:677-687.

36. Smits, P., et al. 2001. The transcription factors L-Sox 5 and Sox 6 are essential for cartilage formation. Dev. Cell. 1:277-290.

37. Ikegawa, S., Sano, M., Koshizuka, Y., and Nakamura, Y. 2000. Isolation, characterization and mapping of the mouse and human PRG4 (proteoglycan 4) genes. Cytogenet. Cell Genet. 90:291-297. 